\title{
As manifestações da cultura popular nordestina em Sorocaba - SP
}

\author{
Amanda Alves Gomes* \\ Neusa de Fátima Mariano**
}

Com base em pesquisa de iniciação científica e em trabalho de conclusão do curso de Geografia, o texto a seguir busca, de forma sintetizada, evidenciar algumas manifestações da cultura popular nordestina presentes no município de Sorocaba, localizado a sudoeste do estado de São Paulo, a aproximadamente $90 \mathrm{~km}$ da capital.

Segundo dados do Centro Cultural de Tradições Nordestinas de SorocabaCCTN, o município possui uma população com cerca de 150 mil nordestinos natos e/ou descendentes, fato que abrange cerca de $25 \%$ do total da população sorocabana.

Ao migrarem, muitos nordestinos se deslocaram - e ainda se deslocam - para a Região Sudeste do país em busca da realização de seus sonhos e de melhor qualidade de vida no que diz respeito ao trabalho, à moradia, à saúde e à educação, entre outros. Como se sabe, a Região que abrange os estados do Maranhão, Piauí, Ceará, Rio Grande do Norte, Paraíba, Pernambuco, Alagoas, Sergipe e Bahia não representa uma área homogênea, sendo, ao contrário, caracterizada por muitas singularidades, principalmente quando analisada sob o âmbito cultural. Assim, ao se deslocar, o migrante não leva somente a si e a sua família, mas também - e essencialmente - carrega consigo a sua cultura, a sua identidade que, numa nova região, se reterritorializa e passa a ser lida como cultura nordestina.

À luz das reflexões de Silva (2007), a migração deve ser concebida como um processo no qual o migrante seja considerado um sujeito na sua plenitude. Ou seja, para além de detentor de força de trabalho, cujas motivações que envolvem o deslocamento ultrapassem a visão econômica. Para a autora:

[...] o migrante insere-se numa realidade social definida por laços sociais (familiares, grupos de vizinhança, valores, ideologias etc), que o caracterizam como pertencente a um determinado espaço social e cultural. Portanto, a denominação abstrata de migrante esconde o conjunto de situações concretas e particulares, que definem sua identidade individual e social. (SILVA, 2007, p. 57).

\footnotetext{
* Graduanda em Geografia pela Universidade Federal de São Carlos - Sorocaba

** Professora do Curso de Licenciatura em Geografia da Universidade Federal de São Carlos Sorocaba.
} 
Há, portanto, a construção de uma nova expressão cultural, de maneira que as manifestações, ainda que separadas dos diferentes momentos da vida, possam vir a ser traduzidas por uma especialização funcional tanto empregadas no tempo, como no espaço (SEABRA, 2003). Assim, tem-se, apesar dos espaços distintos, o tempo sobreposto, através da memória e da renovação do vivido, no tempo atual. Cabe mencionar que se atribui à cultura aqui analisada, um "conjunto das práticas, das técnicas, dos símbolos e dos valores que se devem transmitir às novas gerações para garantir a reprodução de um estado de coexistência social" (BOSI, 1992, p. 16). Neste sentido, o migrante carrega consigo a bagagem cultural da sua origem abrindo mão de alguns elementos, reinventando e ressignificando outros no local de destino. Isso funciona como garantia, ao mesmo tempo, de manutenção da própria identidade e de sobrevivência no novo contexto sociocultural.

A partir de pesquisa bibliográfica e de campo, através de entrevistas com nordestinos (descendentes e sorocabanos) e de participação em festas e atividades de caráter cultural nordestino (promovidas ou não pelo CCTN), além de registros fotográficos, buscou-se manifestações culturais singulares, dinâmicas no tempo e no espaço. Seu cerne dialoga com a contemporaneidade, reafirmando ora tradições nordestinas (ritualísticas ou não), ora a própria identidade socioterritorial, talvez por vir do migrante e da sua necessidade de valorizar suas origens.

Há, no entanto, uma construção histórica no local de destino, no caso, a região norte de Sorocaba, em que a reterritorialização permite a manifestação de identidade(s) nordestina(s), além de criar novas dimensões socioculturais, contribuindo para a produção deste espaço geográfico.

Desse modo, o conhecimento geográfico, perante a espacialização e dinamicidade da cultura, pode analisar as expressões culturais nordestinas trazidas e reinventadas no município de Sorocaba, bem como sua marginalização por parte do poder público.

\section{Migração nordestina em Sorocaba}

Durante o século XIX, Sorocaba recebeu grandes investimentos nas indústrias têxteis e atraiu trabalhadores provenientes de outras regiões do país, além dos contingentes europeus que imigraram para o Brasil. Essas fábricas, que tiveram sua notoriedade até a segunda metade do século $X X$, passaram a dar espaço para novas indústrias especializadas em bens de produção e que procuram descentralizar essas atividades, principalmente da metrópole paulista, e vinculá-las a novas regiões. Com este histórico de desenvolvimento econômico, sobretudo em relação à industrialização, a atração populacional tornou-se inevitável e trouxe para Sorocaba, migrantes de origem nordestina, tanto os que já haviam passado pela metrópole paulistana quanto os que vinham diretamente 
dos estados do Nordeste (COSTA, PÉREZ e SILVA, 2001). Neste contexto, essas pessoas vinham na tentativa de conseguir emprego nas fábricas e instalavam-se nas regiões mais periféricas de Sorocaba.

Segundo os resultados da amostra do Censo Demográfico de 2010, referente à migração da "População residente por lugar de nascimento - Região Nordeste", Sorocaba possui 35.363 habitantes nordestinos natos (IBGE, 2013).

O IBGE (Instituto Brasileiro de Geografia e Estatística) também traz dados do Censo sobre a amostra de "Pessoas naturais da Unidade da Federação, que residiam há menos de 10 anos ininterruptos na Unidade da Federação, por sexo, grupos de idade e lugar de residência anterior", contendo informações sobre a origem dos migrantes presentes no município de Sorocaba há menos de dez anos. Com isso, verifica-se no Gráfico1 que a maior parte dos migrantes nordestinos presentes em Sorocaba, veio do estado da Bahia (591 pessoas), seguido pelos estados da Paraíba (229 pessoas) e de Pernambuco (224 pessoas), do Maranhão (66 pessoas), do Ceará (39 pessoas) e de Sergipe (31 pessoas). Não há dados sobre os estados do Piauí, do Rio Grande do Norte e de Alagoas (IBGE, 2013).

Gráfico 1. Pessoas naturais da Unidade de Federação, que residiam há menos de 10 anos ininterruptos na Unidade de Federação, por sexo, grupos de idade e lugar de residência anterior (2010)

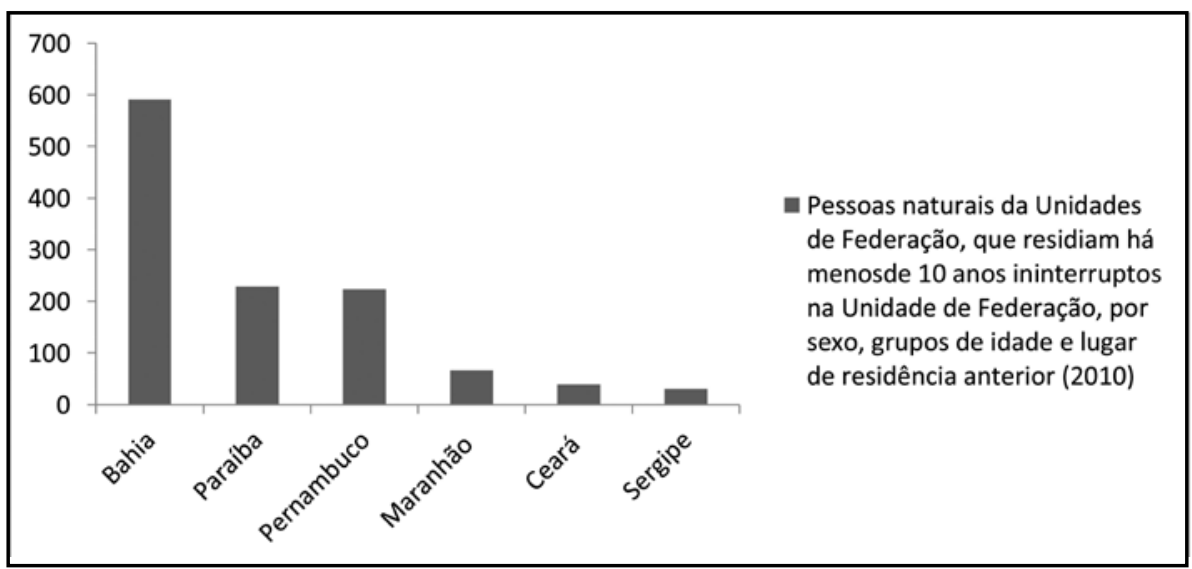

Fonte: http://www.ibge.gov.br. Acessado em julho de 2013.

De modo a completar estas informações, segundo dados do CCTN, o município possui cerca de 150 mil nordestinos, sendo eles natos ou descendentes, fato que abrange por volta de $25 \%$ da população total sorocabana.

Decorrente de processos históricos e espaciais, a migração nordestina em Sorocaba se concentrou e permanece concentrada nas regiões norte e oeste da cidade, onde ainda se percebem resquícios de valorização de sua identidade. 
Porém, dentro do processo histórico da divisão territorial do trabalho, atualmente fica difícil constatar com clareza o fluxo ou preferência de deslocamento e fixação pelos migrantes. Aqueles que já possuem alguma forma de contato, seja familiar ou não, geralmente se concentram junto a seus conhecidos. Porém, aos migrantes cuja perspectiva é incerta e, até certo ponto, solitária, a moradia geralmente é influenciada pela oportunidade de emprego, como verificada na fala de S. R. M.:

\begin{abstract}
Então, o que acontece, eles vêm procurar é... cidade grande. São Paulo... Sorocaba... Né, eles vão até São Paulo, de São Paulo vem prá cá. Eles gostam muito de Sorocaba. É. Eles caem muito aqui em Sorocaba, por quê? Porque é uma cidade, que assim, oferece... num é né, uma cidade grande, porém, uma cidade acolhedora. É uma cidade que assim... tem muita... muito emprego em construção civil. Então, é... eles vêm pra trabalhar justamente nessa área. Informalmente.
\end{abstract}

O processo de globalização, desenvolvido e alimentado no bojo do modo de produção capitalista, tende a homogeneizar (padronizar) as diversas expressões culturais presentes em diferentes regiões do espaço geográfico. Porém, essa (re)produção espacial acaba por acirrar, de forma contraditória, desigualdades e especificidades que as diversificam. Apoiados nessas condições, ainda há locais nos quais costumes antigos sobressaem a quaisquer tendências homogeneizantes e resistem perante a insistência das novas condições de sobrevivência cultural impostas pela economia global-local, numa atitude de autoafirmação identitária.

A diversidade territorial e o processo de regionalização envolvem ações e resultados que aparecem sob diferentes graus e naturezas. Enquanto estas se relacionam às singularidades e especificidades regionais, numa abordagem mais qualitativa que ressalta as diferenças culturais, aqueles se encontram relacionados às particularidades e às desigualdades do espaço, numa esfera quantitativa e limitada. Fruto da globalização, tal relação evidencia a dialética de inclusão-exclusão e de dominância-resistência que se revelam num cenário espacial-geográfico cada vez mais corrompido pelo mercado.

Assim, podemos compreender o fato da região sul da cidade de Sorocaba haver sido designada, historicamente, à reserva do capital e, hoje, estar configurada por condomínios e bairros de classe média alta. Já a região norte, até então com pouco investimento, coube "acolher" a massa de migrantes nordestinos, pois seu passado é de loteamentos de tamanho pequeno ( $5 \mathrm{~m} x$ $25 \mathrm{~m}$ ou $125 \mathrm{~m}^{2}$ ) que, ao passar dos anos, concentrou um número cada vez maior de famílias de baixa renda (COSTA, PÉREZ e SILVA, 2001, s./ p.). Decorre disso e da falta de aproximação entre as classes economicamente mais "baixas" e as "superiores" (que então se encontravam "anestesiadas" pela possibilidade de crescimento social e econômico) uma ocupação da zona norte também pelas 
classes mais abastadas, a partir da especulação imobiliária, embora ainda se apresente um bom contingente populacional de origem nordestina, como destaca J. N. S.: "Então, eu tenho alunos descendentes... tem alunos também que vieram... de lá. No bairro aqui. Eu escolhi o bairro porque tem uma gama de nordestinos aqui. [...] Aqui é Paineiras. Zona Norte de Sorocaba".

Em meio a este novo espaço e aos desafios existentes, a (re)configuração e a (re)estruturação da identidade cultural enfrentam os desafios políticos, econômicos e sociais vigentes, confrontando também a própria intenção homogeneizadora da globalização. A tendência é que haja a "reconstrução da heterogeneidade e da fragmentação via novas desigualdades e recriação da diferença em todos os cantos do planeta" (HAESBAERT apud HAESBAERT, 1999, p. 16).

A este fato, acrescenta Harvey:

[...] quanto menos importantes as barreiras espaciais, tanto maior a sensibilidade do capital às variações do lugar dentro do espaço e tanto maior o incentivo para que os lugares se diferenciem de maneiras atrativas ao capital. $O$ resultado tem sido a produção da fragmentação, da insegurança e do desenvolvimento desigual efêmero no interior de uma economia de fluxos de capital de espaço global altamente unificado (HARVEY, 1989, p. 267).

Deste modo, o tamanho do desafio que o processo migratório enfrenta, instituído de uma identidade cultural ao se configurar sob os diferentes espaços políticos, nasce de uma essência econômica igualmente oportunista e deturpadora. Neste sentido, cabe a observação de J. N. S.:

E há uma elite que coloca aqui a cultura que ela pretende né... [...] Então a cultura que eles fomentam é essa, a cultura de consumo de mercadorias... Não cultura de consumo de valores culturais, dentre os quais a produção musical, por exemplo, que isso é valor. Que faz refletir.

O depoente refere-se à marginalização a qual é colocada a cultura popular, no caso, nordestina, por parte do poder público de Sorocaba, uma vez que contribui com a divulgação da cultura como mercadoria.

\section{A identidade cultural nordestina}

Verifica-se, em Sorocaba, um processo de reterritorialização de migrantes nordestinos que, uma vez instalados no município, construíram suas histórias tendo como referência seu passado na terra natal. A desterritorialização e a posterior reterritorialização trazem, no bojo desse processo, um conjunto de 
manifestações culturais que se fazem presentes no cotidiano, as quais não se dão somente no âmbito da festa - talvez da religiosidade popular - mas também no saber fazer, nas crenças e superstições, na culinária, etc.

Nesse sentido, a memória se faz presente na sua forma coletiva; é a memória como herança daqueles primeiros migrantes que se mantém viva por meio das manifestações culturais como forma de reafirmar a identidade. Há aqui uma conexão, interposição, ou entrelaçamento entre tempo e espaço: dois tempos, dois espaços, dois ritmos de vida, duas realidades que se colocam frente a frente em um mesmo momento histórico. Ora há o reforço da identidade territorial do passado, do local de origem ora a sua negação reafirmando uma identidade da cidade, do urbano paulista que representa "o moderno".

Essa recusa do passado fica evidente quando o migrante, muitas vezes, não quer se identificar como nordestino, para "camuflar-se" perante o preconceito interno e externo a ele próprio. Por isso, acaba negando o CCTN que, como organização associativa de caráter filantrópico, técnico, educativo, de divulgação e promoção da cultura, da tradição e dos costumes do povo nordestino, reafirma e valoriza cada vez mais essa identidade. Também se fazem presentes aqueles que, mesmo sabendo e apoiando a entidade, preferem manter suas expressões culturais originais dentro do próprio lar, junto ao núcleo familiar e de amigos. Ou seja, não manifestam publicamente sua identidade com a cultura nordestina.

O fato é que, alimentando o próprio preconceito ou sendo reprimido de outros modos, economicamente, por exemplo, o migrante se torna muito mais vulnerável aos anseios da globalização e à lógica neoliberal, acelerando ainda mais as transformações culturais. Vale lembrar que, apesar da cultura se reconstruir diante de novas territorialidades, confirma-se, como na fala de um dos entrevistados, a incapacidade das manifestações da cultura popular nordestina se refazerem de modo completo já que, à identidade, atribuem-se também os vínculos pessoais de cada migrante, "deixados para trás" após a partida: “Assim, nunca vai ser igual lá. Porque lá... eu num sei. É um vínculo que... eu num sei como explicar. É uma sensação que você só vai sentir lá, participando lá, porque lá é único" (A. L. S.).

Tratando aqui da cultura nordestina tradicional e de modo a compreendê-la como fruto de complexidades vindas de sua própria origem, toma-se o cuidado de não determiná-la ao alcance da referência utilizada, a qual somente serve de base para apurar o olhar daquela que, frente ao novo meio, ora se reprime, ora se dissemina, porém, sempre se adapta ao novo espaço.

Desse modo, evidencia-se um processo de recriação e/ou ressignificação cultural que, ligado àquele que o permite dentro de si e o identifica como sua raiz, acaba por moldá-lo a cada novo meio. Surgem, assim, novas formas de expressão. Porém, há de se considerar que a manifestação cultural na sua plenitude só se concretiza, para o migrante, no cenário de sua criação original. 


\section{O papel do CCTN em Sorocaba}

Como instituição de caráter filantrópico, o Centro Cultural de Tradições Nordestinas de Sorocaba - CCTN não se apresenta como organização em escala nacional, tampouco em rede. Trata-se de uma instituição local, com estatuto próprio, sem conexões com o conhecido CTN-Centro de Tradições Nordestinas de São Paulo ou qualquer outra organização de caráter similar. Foi fundado e é gerenciado por pessoas que, se encontrando na condição de migrante nordestino, perceberam a necessidade de organização da população cujos direitos, dentre eles, o de expressão cultural, estavam sendo esquecidos e negados no local de destino.

Localizado à rua Sarutaiá, no centro de Sorocaba, no início de suas atividades em 2005, o CCTN contava com o apoio do grupo de músicos e dançarinos Bambaê di Fulô e realizava eventos de culinária nordestina, apresentação de bandas e cursos. Por incômodo da vizinhança, o CCTN mudou de endereço e passou a ocupar, a partir de 2009, a sede da Avenida Itavuvu, local mais periférico. Com isso, o fluxo de frequentadores diminuiu devido a distância do local em relação à sede anterior, que era central e de acesso mais fácil. Durante o tempo em que permaneceu na Avenida Itavuvu, zona norte de Sorocaba, o CCTN desenvolveu atividades junto à comunidade, tais como oficinas de bordado, capoeira, ginástica, forró, canto de repente, maracatu, jantares temáticos, entre outros.

Cumprindo e realizando festividades fixadas no seu calendário oficial, o CCTN promoveu, em 24 de junho de 2012, o Dia Municipal do Nordestino e entre os dias 24 e 30 do mesmo mês, a Semana da Nordestinidade ${ }^{1}$, em 8 de outubro, o Dia Nacional do Nordestino e, em 13 de dezembro do mesmo ano, o Dia das Tradições Nordestinas (CCTN, 2012).

Para homenagear os migrantes, em 2003 a Câmara de Vereadores de Sorocaba promulgou a Lei que instituiu o Dia das Tradições Nordestinas. A data foi instituída para homenagear cerca de 150 mil pessoas, entre migrantes nordestinos e seus descendentes que existem na cidade, segundo o CCTN (Centro Cultural de Tradições Nordestinas). O contingente foi calculado com um levantamento das famílias que chegaram nos últimos 60 anos: é $25 \%$ da população local. (SOROCABA GLOBALIZADA, abril de 2013).

Próximo de fechar sua sede devido ao alto custo para a sua manutenção, o CCTN continha cerca de duzentos cadastros de frequentadores, número pequeno, segundo sua presidente Selma Regina da Silva Araújo, resultante da problemática do próprio "preconceito" de expor e assumir suas origens e sua condição de migrante. 
Sem o apoio concreto da Prefeitura Municipal ou de outros órgãos públicos ou privados, sustentar economicamente a sede do CCTN passou a ser um desafio durante alguns meses até que o contrato de aluguel do imóvel não pode mais ser renovado. Em busca de soluções, Selma procurou os direitos do CCTN, porém, houve reação contrária por parte da política administrativa cultural da cidade, o que somente reforçou os interesses em que se colocam os investimentos culturais locais, sob aquilo que foi "verticalmente" instituído como a "verdadeira identidade sorocabana" - baseada no caráter de uma história simplificada, de repressão e marginalização das baixas classes sociais passadas e presentes, e de movimentos que, de alguma forma, desestruturam toda a hierarquia local.

Apesar da dificuldade de não possuir mais uma sede própria, o CCTN continuou a promover eventos como a 5 a Festa de Tradições Nordestinas, realizada em dezembro de 2013, no centro de Sorocaba. Porém, o início do ano de 2014 trouxe novas perspectivas à instituição, pois, em março, ao completar exatos dez anos de muita paciência e dedicação em favor de um espaço com apoio da prefeitura sorocabana, o CCTN finalmente recebeu uma área para construção de uma nova sede. Esta ficará na zona norte da cidade e, segundo Selma, terá museu, salas de aula, biblioteca, "cordelteca", dentre outras atividades que devem surgir quando a sede estiver em funcionamento. Tal fato representa uma possibilidade e uma garantia a mais para a continuidade e a repercussão da identidade cultural nordestina no município de Sorocaba, em respeito a seus migrantes.

\section{Expressões da cultura nordestina em Sorocaba}

Os vínculos com o local de origem nunca são completamente desfeitos no processo migratório. Mesmo que não haja conexões reais e concretas, há sempre a memória do lugar, que participou da construção da personalidade do migrante, de forma a compor a sua história. Nos casos apresentados em Sorocaba, os migrantes entrevistados disseram ter contato com a cidade de origem e, sempre que possível, retornam para ela a fim de rever parentes ou mesmo vivenciar manifestações da cultura nordestina como as Festas Juninas.

Constatou-se ainda que as manifestações culturais que também acontecem em Sorocaba possuem semelhanças com aquelas provenientes do Nordeste, porém assumem perspectivas distintas de acordo com a própria rotina e a intenção do migrante. E, quando realizadas por órgãos oficiais da cidade, a exemplo da Festa Junina, podem assumir um caráter mais de celebração oficial do que festivo, mais comercial do que cultural.

Apesar das tentativas de cooptação da expressão popular pela lógica de mercado, exemplos das manifestações da cultura nordestina puderam ser encontrados em Sorocaba, conforme brevemente apresentado a seguir.

A Arte em Barro é uma das expressões nordestinas em que o artesanato é produzido em argila e pintado à mão e que foi exposta durante a festa "Arraiá 
Fora do Eixo". Este chama a atenção por seu aspecto único e a representação de bonecas, cujas peças trazem o cotidiano e recortes de temáticas e personagens históricos do Nordeste, como as baianas, os cangaceiros, os retirantes, etc..

Também integrando a identidade nordestina, o Bumba-meu-boi representa um produto da tríplice miscigenação com influência indígena, negra e portuguesa, cujo folguedo possui enredos variantes no Maranhão. A versão mais popular remete ao desejo de uma escrava comer a língua do boi que, então, é morto por seu marido (CASCUDO, 2001, p. 80). Assim como o Coco, essa manifestação é vivenciada no Núcleo de Cultura Popular Leão da Vila, do Centro Cultural Quilombinho, em Sorocaba.

Segundo Câmara Cascudo (2001, p. 147), o Coco de Roda remete a uma dança nordestina presente nos estados da Paraíba, do Rio Grande do Norte, de Alagoas e do Piauí. Com raízes africanas, nos dois primeiros estados citados, ele assimila alguns aspectos da dança e composição dos integrantes. Já no Piauí, ele apresenta formas variantes de dança e ritmo.

Sendo uma das representações da cultura nordestina mais cultuada em lares, festas e casas noturnas de Sorocaba, o Forró se caracteriza por ser um ritmo e uma dança mestiços de influências culturais de toda a Região Nordeste. No dicionário de Câmara Cascudo (2001, p. 249), o aparecimento do forró (música e dança) remete à segunda metade do século XX com a migração de nordestinos para Brasília, Rio de Janeiro e São Paulo. O forró faz parte do calendário de algumas casas noturnas de Sorocaba que buscam o contato com o ritmo, seja ele tradicionalmente pé-de-serra ou "universitário". Grupos sorocabanos como o Trio Macaíba, o Velha Maromba e o Forró Euzébio são exemplos de artistas que integram estes eventos.

Já a presença da Capoeira, que possui origens mais remotas em Angola, antes representava uma "forma de luta, muito valiosa na defesa da liberdade, de fato ou de direito do negro liberto" (CARNEIRO apud CASCUDO, 2001, p. 111). Em Sorocaba, a capoeira possui diversos espaços de ocorrência, como por exemplo a Associação Capoeira Liberdade, dos quais muitos mestres são nordestinos.

Assim como o Coco e a Capoeira, o Maracatu possui raízes africanas que representam, há mais de quatrocentos anos, a música e as tradições dos escravos provenientes da África. Ele integra dança, ritmo e canções tradicionais do Nordeste e, dentre seus tipos, tem-se o de Baque Virado (ou Maracatu Nação) que surgiu em Pernambuco durante o período escravista, entre os séculos XVII e XVIII, e representava as coroações e os autos do Rei do Congo. Está presente na cidade por intermédio de grupos como o Leão da Vila, a Comunidade do Tambor, o Matinta Pereira, entre outros. 


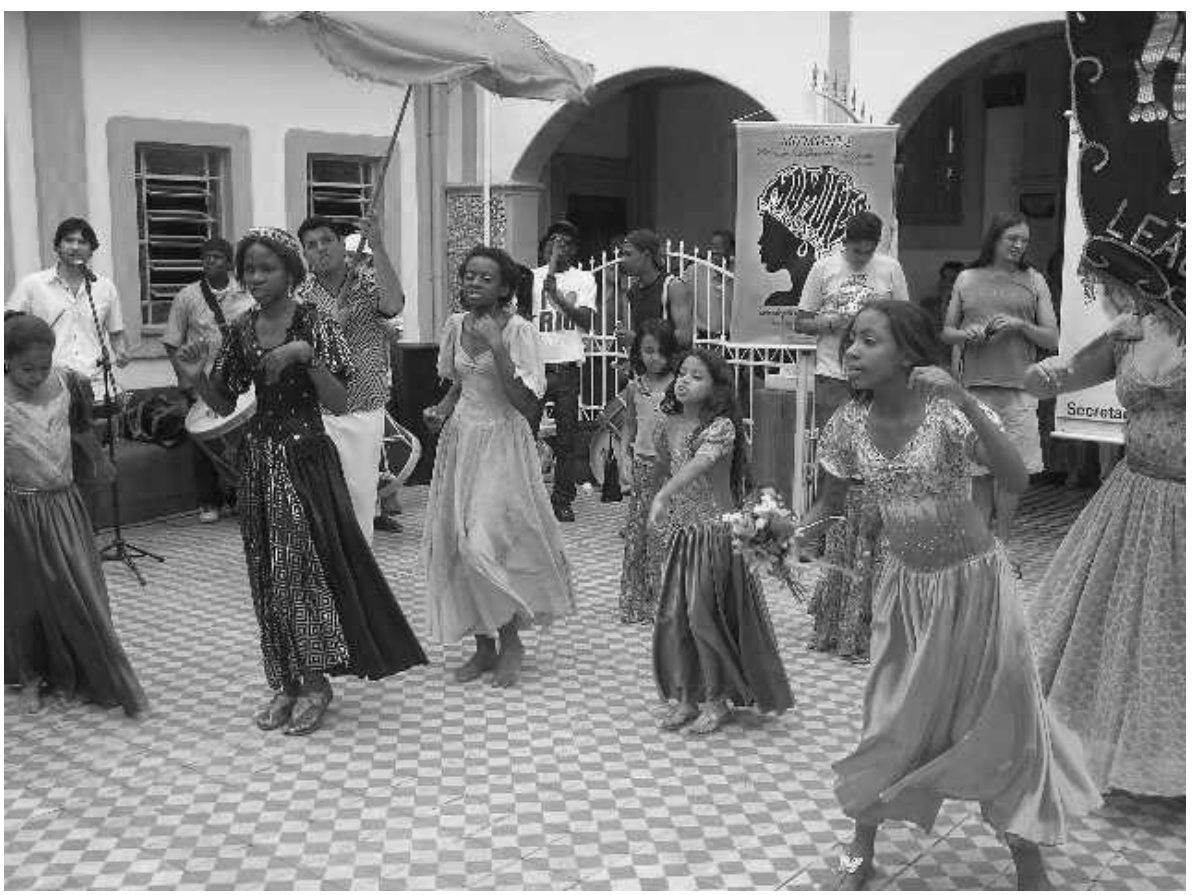

Maracatu Leão da Vila

Autora: GOMES, Amanda Alves. Data: 20/11/2010.

Artistas locais acabam promovendo eventos informais que culminam no Samba de Roda, também representado pelo Núcleo de Cultura Popular Leão da Vila. Segundo o Instituto do Patrimônio Histórico e Artístico Nacional (IPHAN), a dança é mais conhecida pela região do Recôncavo Baiano e teria surgido nos anos de 1860. De raízes na cultura dos escravos africanos presentes na Bahia, teve influência também da cultura lusitana no arranjo instrumental.

O Canto de Repente é o desafio entre cantadores sertanejos. Segundo Câmara Cascudo (2001, p. 584), "repente é a resposta inesperada e feliz, aturdindo a improvisação do adversário". Para Severino Uchoa (apud CASCUDO, 2001), o Canto de Repente "é a resposta rimada proferida em meio a uma conversa, o esclarecimento ou a declamação em versos. Caracteriza-se pela surpresa do tema e prontidão da rima". O repente pode ainda se caracterizar como uma forma de protesto e é uma expressão tão espontânea que não necessita de um palco, podendo acontecer no cotidiano, fato que dificulta o mapeamento de suas ocorrências. O CCTN é um canal que permite esta manifestação cultural nordestina, a exemplo da foto, com a dupla de repentistas. 


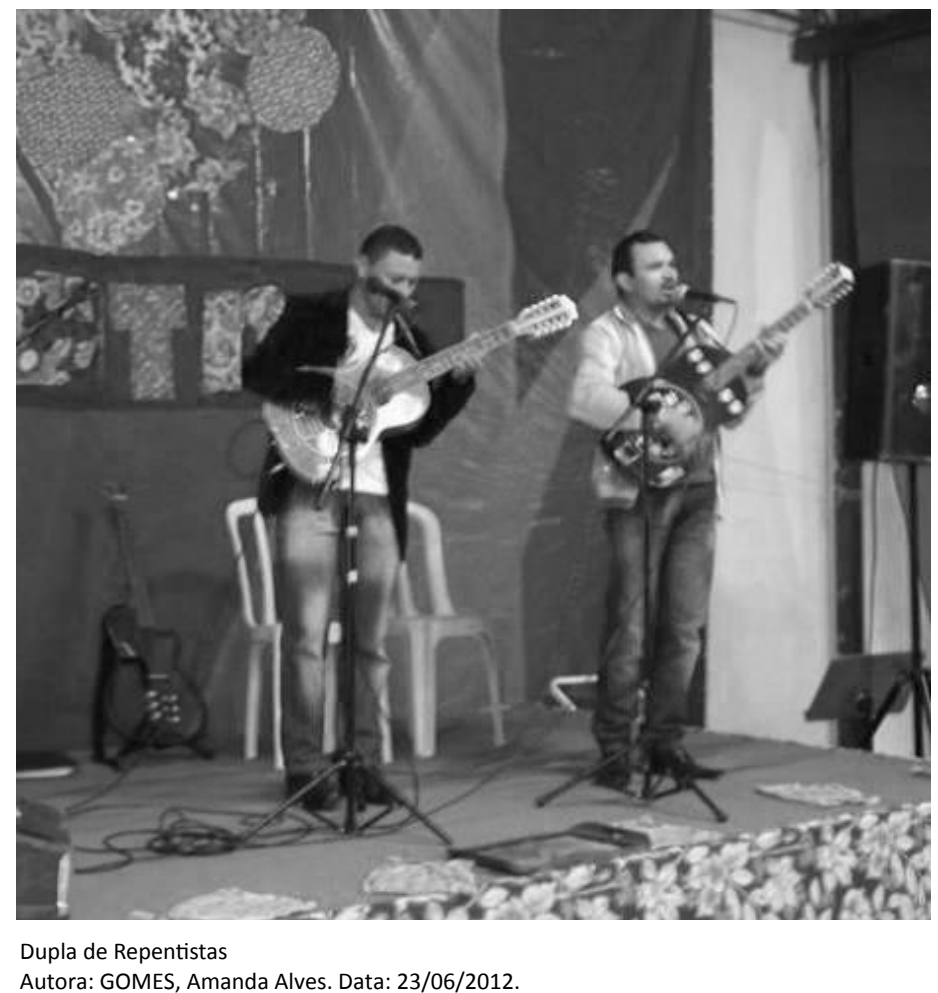

Também presente nos eventos do CCTN está o Cordel. Historicamente, ele vem dos povos conquistadores greco-romanos, fenícios, cartagineses, saxões etc., chegando à Península Ibérica (Portugal e Espanha) em meados do século XVI, sob os nomes de "pliegos sueltos" (Espanha) e "folhas soltas" ou "volantes" (Portugal). No Brasil, instalou-se na Bahia (Salvador) através da colonização e assim se difundiu para todo o Nordeste. Em dezembro de 2011, o CCTN promoveu um encontro de cordelistas, o que demonstra o quão importante é o Centro para as manifestações da cultura popular nordestina e a manutenção da identidade.

As rendas Renascença e Filé são outro exemplo de beleza e delicadeza da cultura nordestina. $O$ seu tecer pode ocorrer pontualmente, com caráter espontâneo, ou em locais próprios promovidos pelo poder público como as feiras de artesanato. A renda Renascença, segundo a rendeira entrevistada C. L. M. B. S., tem suas origens nas proximidades das cidades de Pesqueira e de Vila de Simbres, no interior de Pernambuco, onde foi ensinada às mulheres indígenas pelos colonizadores europeus. Este artesanato, às vezes considerado banal, precisa ser valorizado, não só pela tradição, mas como verdadeira obra de arte. Já a renda Filé, segundo Valença e Melo (2010), é mais comum no estado da Paraíba e se caracteriza por ser utilizada em produtos mais "'rústicos', sem 
muito acabamento, como em toalhas e passadeiras de mesa, roupas artesanais". Além dos eventos promovidos pelo CCTN, esta renda também está presente em feiras de artesanato que ocorrem nas praças da cidade, como mais uma forma de reafirmar a identidade cultural de expressão nordestina trazida pelo processo migratório.

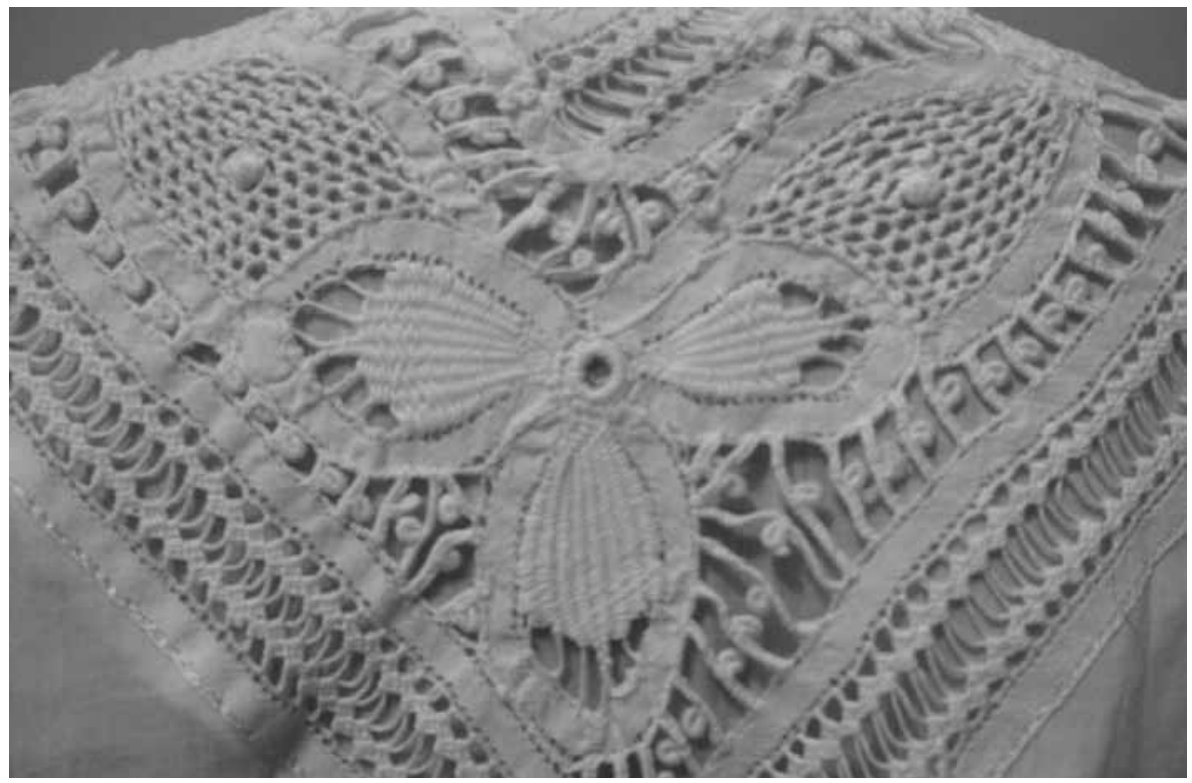

Renda Renascença

Autora: GOMES, Amanda Alves. Data: 01/12/2013.

Acompanhando a rotina no lar ou em restaurantes e em muitos eventos relacionados à cultura nordestina em Sorocaba, a Comida Típica merece destaque pela sua forma de se difundir na cidade, seja através dos migrantes, seja pela apreciação por parte dos próprios sorocabanos. Um dos pratos típicos nordestinos presente no dia a dia é o Baião de Dois, feito com arroz e feijão misturados e, conforme o estado ou a região nordestina de origem pode ser incrementado com queijo, tempero forte, linguiça etc. Além de tapioca, curau, acarajé, cocada, carne de sol (charque) e outros alimentos mais popularizados nos lares, pratos como mungunzá, bolo de carne empanado, baião de dois, buchada de bode, bobó de camarão, manteiga de garrafa e galinhada podem ser encontrados nos lares de migrantes e descendentes que mantêm a sua identidade na culinária nordestina. Ainda, em casos como o da família do entrevistado A. L. S., pode-se verificar a busca por ingredientes e temperos no Mercado Municipal de Sorocaba, cuja presença de barraca específica de alimento do Norte e do Nordeste brasileiro contribui para a manutenção da identidade do território de origem, realizada em um novo contexto socioterritorial. 
Em Sorocaba, verificam-se ao menos quatro restaurantes de nomes e pratos nordestinos. São eles: "Cantinho do Nordeste" e "Rainha do Norte", "Feijão de Corda", "Delícia do Nordeste", localizados na zona Norte, Central e Leste, respectivamente.

\section{Considerações Finais}

Diante de todo o material teórico assimilado, somado aos relatos orais, constatou-se que, no município de Sorocaba, há o predomínio de migrantes e descendentes advindos dos estados da Bahia, da Paraíba e de Pernambuco. No entanto, as manifestações da cultura popular nordestina ainda são restritas a poucos lugares. Enquanto o CCTN permaneceu sem sua sede para a promulgação e o resgate da identidade territorial nordestina, as manifestações culturais acabaram por se limitar a espaços como o Centro Cultural Quilombinho, algumas casas noturnas e nas próprias residências de migrantes e descendentes, localizadas principalmente nos bairros das zonas norte e oeste da cidade.

Evidencia-se, portanto, que em Sorocaba, a identidade e a manifestação da cultura popular nordestina se encontram, assim como seus detentores, marginalizados perante a sociedade local. Por mais que ela exista e seja disseminada, exaltada e vivenciada por alguns, continua escondida pelo poder público sorocabano que, ao negar apoio, credibilidade e respeito, inibe - a partir de mecanismos políticos que excluem a participação dessa cultura no circuito administrativo político cultural da cidade - a sua reconstrução espacial e cotidiana na vida de velhos e novos migrantes, bem como de seus descendentes. Desse modo, ela é ora fragmentada de "cima para baixo" ora "de baixo para cima", em um ciclo que desconstrói o que um dia fora sonho e reconstrói o que é possível na realidade encontrada, nesse "encontro com a terra prometida", para lembrar Ariovaldo Umbelino de Oliveira. 


\section{Notas}

1 - Embora não tenha havido uma atenção maior ao termo "Nordestinidade" para nomear a Semana, acredita-se que o emprego de tal palavra tenha a ver com a diversidade cultural proveniente dos estados da Região Nordeste do país, de forma a contemplar as identidades dos migrantes nordestinos em Sorocaba.

\section{Referências}

BOSI, A. Dialética da colonização. São Paulo: Companhia das Letras, 1992.

CASCUDO, L. C. Dicionário do Folclore Brasileiro. 11. ed. São Paulo: Global, 2001.

CCTN. Centro Cultural de Tradições Nordestinas de Sorocaba. Disponível em: http://www. cctn.org.br. Acesso em: XX abr. 2012.

COSTA, A. Mitos sobre o sertão: realidade, exageros ou simples mentiras? Portal Virtual Barcelona, RN, Brasil. Disponível em: http://www.barcelonarn.tk. Acesso em: XX fev. 2013.

COSTA, E. M. A. da; PÉREZ, N. M.; SILVA, P. C. da. "Só volto lá quando puder comprar óculos escuros": histórias de viagens do Nordeste a Sorocaba. Scripta Nova Revista Electrónica de Geografia y Ciencias Sociales. Universidade de Barcelona, ano 50, n. 94, ago. 2001. Disponível em: http://www.ub.edu/geocrit/sn-94-50.htm. Acesso em: XX abr. 2012.

HAESBAERT, R. Região, diversidade territorial e globalização. GEOgraphia, Universidade Federal Fluminense, ano 1, n. 1, 1999.

HARVEY, D. Condição pós-moderna. São Paulo: Loyola, 1989.

INSTITUTO BRASILEIRO DE GEOGRAFIA E ESTATÍSTICA. Disponível em: <www.ibge.gov.br>. Acesso em: maio/2013.

MELO, M. T.; VALENÇA, L. A. A inserção da renda filé no conceito do novo luxo. In: IV Encontro de Ensino, Pesquisa e Extensão da Faculdade Senac. 2010. Recife. Anais eletrônicos... Disponível em: http://www.faculdadesenacpe.edu.br/encontro-de-ensino pesquisa/2011/IV/anais/comunicacao/005_2010_ap_oral.pdf. Acesso em: XX jun. 2013.

SEABRA, O. Urbanização e fragmentação: cotidiano e vida de bairro na metamorfose da cidade em metrópole, a partir das transformações do Bairro do Limão. 2003. XXX f. Tese (Livre-docência) Universidade de São Paulo, 2003.

SEADE, 2007. Disponível em: www.seade.gov.br/economiapaulista.pdf. Acesso em: 15 nov. 2012.

SILVA, M. A. M. Contribuições metodológicas para a análise das migrações. (p. 57-68). HEIDEMANN, H. D.; SILVA, S. A. Simpósio Internacional. Migração: nação, lugar e dinâmicas territoriais. São Paulo: DG/USP, UGI, Associação Editorial Humanitas, 2007.

SOROCABA GLOBALIZADA. Terra de todos os povos. Sorocaba, 2013. Disponível em: http:// www.sorocabaglobalizada.com.br/conteudo/mundo 


\title{
RESUMO
}

Objetivou-se, nesse estudo, analisar espacialmente as manifestações da cultura nordestina presentes no município de Sorocaba, decorrentes de movimentos migratórios atraídos pela oportunidade de emprego local. Coube ao trabalho identificar parte desse cenário cultural nordestino na tentativa de se compreender os locais que abrange, bem como se estes permanecem uniformes ou fragmentados, homogêneos ou heterogêneos no cotidiano do migrante e do descendente nordestino. Buscou-se, ainda, entender a presença do CCTN (Centro Cultural de Tradições Nordestinas) de Sorocaba na vida dos migrantes e dos descendentes, bem como na política, na cultura e na sociedade local como um todo.

Palavras-chave: Cultura popular, Migração, Identidade nordestina.

\begin{abstract}
The objective of this study is to spatially analyze the manifestations of the Brazilian Northeastern culture present in the city of Sorocaba, resulted from migration movements attracted by employment opportunities. It aimed to identify part of this Northeastern cultural scene in an attempt to understand the places over which it is spread, as well as if they remain uniform or fragmented, heterogeneous or homogeneous in the migrant and Northeastern descendants' daily life. Moreover, we sought to understand the presence of CCTN (Centro Cultural de Tradições Nordestinas) of Sorocaba in the lives of migrants and descendants, as well as in local politics, culture and society as a whole.
\end{abstract}

Keywords: Popular culture, Migration, Brazilian Northeastern identity. 
